Editorial

\title{
People with Disabilities: The Overlooked Consumers
}

\author{
Kirsi Laitala * and Anita Borch \\ (K.L.), anita.borch@oslomet.no (A.B.) \\ * Corresponding author \\ Submitted: 31 December 2018 | Published: 31 January 2019
}

Consumption Research Norway-SIFO, Oslo Metropolitan University, 0130 Oslo, Norway; E-Mails: kirsi.laitala@oslomet.no

\begin{abstract}
This thematic issue aims at developing and disseminating knowledge about how consumption can promote and inhibit social participation and social inclusion through increased access to and use of marketplaces, goods and services. This editorial briefly presents the topic and summarises the different articles published in the issue.
\end{abstract}

\section{Keywords}

accessibility; consumption; disability; equal rights

Issue

This editorial is part of the issue "People with Disabilities: The Overlooked Consumers", edited by Anita Borch and Kirsi Laitala (Consumption Research Norway-SIFO, Norway).

(C) 2019 by the authors; licensee Cogitatio (Lisbon, Portugal). This article is licensed under a Creative Commons Attribution 4.0 International License (CC BY).

\section{Introduction}

We are all consumers with varying levels of abilities who acquire, use and dispose of goods and services in everyday life. Access to vital consumer goods and services is linked to the human right of being a full member of society and living an independent life. However, consumers with disabilities face greater barriers due to reduced access to products and services, despite the legislation that has been implemented to enhance the situation (Kaufman-Scarborough, 2015). It is estimated that between $15.6 \%$ and $19.4 \%$ of the world's adult population live with some kind of disability (WHO, 2011). In fact, most of us will at some point in our lives experience short- or long-term disability due to illness, accident or age (WHO, 2011).

This thematic issue aims at developing and disseminating knowledge about how consumption can promote and inhibit social participation and social inclusion through increased access to and use of marketplaces, goods and services. The authors of this thematic issue address the challenges that consumers with disabilities face in everyday life and examine whether some markets, products or services are more challenging to ac- cess than others. Furthermore, some of the included articles analyse which interventions have been implemented at different levels to improve the situation of consumers with disabilities; others explore how well the interventions function while pointing out potential areas for improvement. The articles encompass the experiences of consumers with varying levels and types of disabilities, including mental, cognitive, physical, visual or hearing ones. Based on exploratory qualitative studies, the authors discuss the experiences of this often overlooked consumer group and suggest directions for further research.

\section{Short Presentation of the Articles}

In the first article, Daniels (2019) criticises the way mothers with disabilities are treated by the society, including inadequate healthcare services and non-accessible goods and services at consumer markets. Based on autoethnographic material and literature on the topic, she gives examples of the discrimination encountered in their everyday lives. She urges the need for recognition and adequate support to ensure that disabled women can get smoother transitions into motherhood. 
Laitala and Klepp (2019) describe the daily difficulties people with ostomy, or chronic skin disease, face as clothing consumers. They explore the various challenges, as well as the related coping strategies, people use for concealing the condition and the connected bodily secretions, but they also highlight the potential for social exclusion when these strategies fail.

Borch and Strandbakken (2019) show that the evaluation of new ideas for technologies that improve energy efficiency vary somewhat between people with and without mild forms of disabilities. People with mild forms of disabilities show more engagement, likely due to their experiences with increased needs and economic constraints. Their study indicates that it is likely beneficial to include people with disabilities in the innovation processes in order to make the new technologies accessible to larger portion of the population.

Samuels (2019) studies how inclusive music making with accessible technologies contributes to the lives of participants with different abilities and how the workshops contribute to improving their confidence, creativity and social skills, thus having a broader impact on social inclusion. Mainstream consumer music technology devices can be made more accessible with adaptions, but at the same time, the main challenge in the workshops is the use of these technical tools that demand focus from the facilitator away from the participants.

Kaufman-Scarborough (2019) shows that many restaurants and venues provide either incomplete or incorrect accessibility information, which does not comply with civil rights laws in the USA. The information provisions for different types of disabilities vary, and restaurants usually cover information only for consumers with physical disabilities; the larger venues are better at also informing consumers with vision, hearing and sensory disabilities. Kaufman-Scarborough calls for a universally regulated communication design for accessibility information.

Closing this thematic issue is a commentary by Warnicke (2019) who shows that deaf citizens in Norway do not have equal access to make emergency calls as other citizens; the situation in Sweden is better, however, but limitations still exist. Warnicke recommends that social services must meet all accessibility requirements to protect the rights of every citizen.

\section{Conclusions}

Overall, the authors show that despite improved accessibility and non-discrimination legislation and existing inclusive design principles, many products, services or marketplaces remain difficulty to access for this overlooked consumer group (Noonan, 1997/2007). There is a need not only to enforce the universal inclusion design principles but also to raise awareness in society in order to fight unintended discrimination that often occurs at the unconscious level. The authors suggest various strategies, such as the inclusion of consumers with disabilities in innovation processes, to ensure that a range of adaptive solutions become easily accessible to meet needs of a diverse range of people. These articles also highlight how including consumers with disabilities in the study adds another perspective to consumption research that enriches our understanding of the studied field as such.

\section{Acknowledgements}

This issue has been made possible by the strategic research priority area "Inclusive Consumption", focusing on vulnerable consumers, at the Consumption Research Norway-SIFO, Oslo Metropolitan University.

\section{Conflict of Interests}

The authors declare no conflict of interest.

\section{References}

Borch, A., \& Strandbakken, P. (2019). User involvement of people with mild disabilities in technology innovations: Does it make a difference? Social Inclusion, 7(1), 136-151.

Daniels, J. N. (2019). Disabled mothering? Outlawed, overlooked and severely prohibited: Interrogating ableism in motherhood. Social Inclusion, 7(1), 114-123.

Kaufman-Scarborough, C. (2015). Social exclusion. A perspective on consumers with disabilities. In K. Hamilton, S. Dunett, \& M. Piacentini (Eds.), Consumer vulnerability. Conditions, contexts and characteristics (pp. 157-169). New York, NY: Routledge.

Kaufman-Scarborough, C. (2019). Publicly-researchable accessibility information: Problems, prospects and recommendations for inclusion. Social Inclusion, 7(1), 164-172.

Laitala, K., \& Klepp, I. G. (2019). Dressing a demanding body to fit in: Clean and decent with ostomy or chronic skin disease. Social Inclusion, 7(1), 124-135.

Noonan, T. (2007). The overlooked consumers: $20 \%$ of the Australian population with disabilities and older people. Surry Hills: Australian Human Rights Commission. Retrieved from www.humanrights.gov.au/ our-work/disability-rights/publications/overlookedconsumers-20-australian-population-disabilities\#_ Toc176876012 (Original work published 1997)

Samuels, K. (2019). The Drake music project Northern Ireland: Providing access to music technology for individuals with unique abilities. Social Inclusion, 7(1), 152-163.

Warnicke, C. (2019). Equal access to make emergency calls: A case for equal rights for deaf citizens in Norway and Sweden. Social Inclusion, 7(1), 173-179.

WHO. (2011). World report on disability. Malta: WHO. Retrieved from whqlibdoc.who.int/publications/2011/ 9789240685215_eng.pdf?ua=1 


\section{About the Authors}
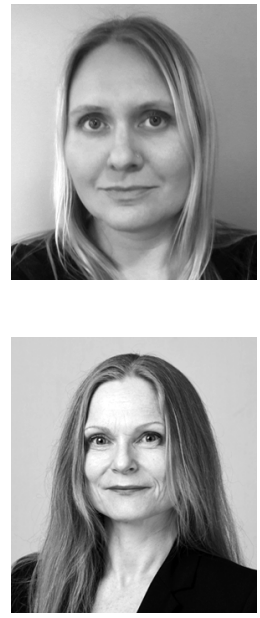

Kirsi Laitala is a Senior Researcher at Consumption Research Norway-SIFO, Oslo Metropolitan University, where she has been working with textile and consumer research since 2001 . Her educational background is in textile engineering and she holds a PhD in Product Design. Laitala's main research areas are sustainability, clothing consumption and vulnerable consumers. She uses interdisciplinary research methods that often combine material studies of textiles with consumer studies, and qualitative methods with quantitative surveys.

Anita Borch holds positions as Head of Research and Research Professor at Consumption Research Norway-SIFO, Oslo Metropolitan University. She also leads an internal project at SIFO entitled "Inclusive Consumption" focusing on, among other issues, people with disabilities. Her scientific publications, since 1994, cover a range of different consumer-related subjects. 